\title{
IIIII The Development and Evaluation of an Online Healthcare Toolkit for Autistic Adults and their Primary Care Providers
}

Christina Nicolaidis, $M D, M P H^{1,2,3}$, Dora Raymaker, $P h D^{7,3}$, Katherine McDonald, $P h D^{3,4}$, Steven Kapp, $M S^{3}$, Michael Weiner, MD ${ }^{3,5,6,7}$, Elesia Ashkenazy, $B A^{3}$, Martha Gerrity, MD, MPH, PhD ${ }^{2,3,8}$, Clarissa Kripke, $M D^{3,9}$, Laura Platt, MD ${ }^{1,10}$, and Amelia Baggs ${ }^{3}$

${ }^{1}$ Regional Research Institute, School of Social Work, Portland State University, Portland, OR, USA; ${ }^{2}$ Department of Medicine and School of Public Health, Oregon Health \& Science University, Portland, OR, USA; ${ }^{3}$ Academic Autism Spectrum Partnership in Research and Education, Portland, OR, USA; ${ }^{4}$ Department of Public Health, Food Studies and Nutrition, Burton Blatt Institute, Syracuse University, Syracuse, NY, USA; Indiana University Center for Health Services and Outcomes Research, Indianapolis, IN, USA; ${ }^{6}$ Regenstrief Institute, Inc., Indianapolis, IN, USA; ${ }^{7}$ Center for Health Information and Communication, Department of Veterans Affairs, Veterans Health Administration, Health Services Research and Development Service CIN 13-416, Richard L. Roudebush VA Medical Center, Indianapolis, IN, USA; ${ }^{8}$ Veterans Affairs Portland Health Care System, Portland, OR, USA; ${ }^{9}$ Department of Family and Community Medicine, University of California, San Francisco, San Francisco, CA, USA; ${ }^{10}$ School of Medicine, Duke University, Durham, NC, USA.

BACKGROUND: The healthcare system is ill-equipped to meet the needs of adults on the autism spectrum.

OBJECTIVE: Our goal was to use a community-based participatory research (CBPR) approach to develop and evaluate tools to facilitate the primary healthcare of autistic adults.

DESIGN: Toolkit development included cognitive interviewing and test-retest reliability studies. Evaluation consisted of a mixed-methods, single-arm pre/postintervention comparison.

PARTICIPANTS: A total of 259 autistic adults and 51 primary care providers (PCPs) residing in the United States.

INTERVENTIONS: The AASPIRE Healthcare toolkit includes the Autism Healthcare Accommodations Tool (AHAT) - a tool that allows patients to create a personalized accommodations report for their PCP-and general healthcare- and autism-related information, worksheets, checklists, and resources for patients and healthcare providers.

MAIN MEASURES: Satisfaction with patient-provider communication, healthcare self-efficacy, barriers to healthcare, and satisfaction with the toolkit's usability and utility; responses to open-ended questions.

KEY RESULTS: Preliminary testing of the AHAT demonstrated strong content validity and adequate test-retest stability. Almost all patient participants (>94\%) felt that the AHAT and the toolkit were easy to use, important, and useful. In pre/post-intervention comparisons, the mean number of barriers decreased (from 4.07 to $2.82, p<$ 0.0001 ), healthcare self-efficacy increased (from 37.9 to 39.4, $p=0.02$ ), and satisfaction with PCP communication improved (from 30.9 to $32.6, p=0.03$ ). Patients stated that the toolkit helped clarify their needs, enabled them

ClinialTrials.gov Identifier: NCT01579669

Electronic supplementary material The online version of this article (doi:10.1007/s11606-016-3763-6) contains supplementary material, which is available to authorized users.

Received December 23, 2015

Revised May 3, 2016

Accepted May 17, 2016

Published online June 6, 2016 to self-advocate and prepare for visits more effectively, and positively influenced provider behavior. Most of the PCPs surveyed read the AHAT (97\%), rated it as moderately or very useful $(82 \%)$, and would recommend it to other patients $(87 \%)$.

CONCLUSIONS: The CBPR process resulted in a reliable healthcare accommodation tool and a highly accessible healthcare toolkit. Patients and providers indicated that the tools positively impacted healthcare interactions. The toolkit has the potential to reduce barriers to healthcare and improve healthcare self-efficacy and patient-provider communication.

KEY WORDS: autism; adults; community-based participatory research; primary care; healthcare interactions.

J Gen Intern Med 31(10): 1180-9

DOI: $10.1007 / \mathrm{s} 11606-016-3763-6$

(C) Society of General Internal Medicine 2016

\section{BACKGROUND}

Autism is increasingly being recognized and diagnosed, with current estimates that 1 in 68 children are autistic. ${ }^{1}$ Though often considered a childhood condition, autism persists throughout the lifespan, with no difference in prevalence by age and likely no change in the true prevalence of autism over time. ${ }^{2,3}$ Due to changes in diagnostic criteria and their application, many autistic individuals are receiving a first diagnosis as adults. ${ }^{4}$ Furthermore, the large cohort of children diagnosed in the last two decades is now approaching, or has entered, adulthood. Yet resources and services for autistic adults remain extremely scarce. ${ }^{5}$

This scarcity is particularly apparent in healthcare. Although most autistic adults may not be seeking healthcare to address or "treat" autism, they still require care for non-autism-related health issues and co-occurring conditions, such as seizures, anxiety, sleep disturbances, and gastrointestinal disorders. ${ }^{6-8}$ Autistic adults face many barriers to receiving healthcare. A majority of 
primary care providers (PCPs) lack the training necessary to care for autistic adults. ${ }^{9}$ Moreover, autism is characterized by atypical communication and interpersonal relationships - factors that are critically important for effective healthcare interactions. Our prior survey found that autistic adults had a greater number of unmet health needs, lower use of preventive services, higher use of the emergency department, and lower ratings of patient-provider communication and healthcare self-efficacy than did non-autistic adults. ${ }^{10}$ Autistic adults also reported a greater overall number of barriers to healthcare and numerous autism-specific barriers to care. ${ }^{11}$ In our prior qualitative study, autistic patients and their supporters described both positive and problematic healthcare interactions, illuminating a complex interplay between an individual's autistic characteristics, the healthcare provider's knowledge and attitudes about autism, and the healthcare system. ${ }^{12}$ For example, autistic patients described healthcare providers making incorrect assumptions about their abilities and needs, being unwilling to accommodate written communication, or using inaccessible language. Interactions were improved when supporters were appropriately incorporated, healthcare facilities were accessible, and clinicians showed a willingness to provide other accommodations.

Our objective was to use a community-based participatory research (CBPR) approach to create and evaluate an online healthcare toolkit for autistic adults and their PCPs. This paper describes a series of three studies used to develop and evaluate the toolkit: a cognitive interview study to assess the content validity of the Autism Healthcare Accommodations Tool (AHAT) survey and reports; a 2-week test-retest reliability study to assess the AHAT's stability over time; and a pre/postintervention study evaluating use of the full healthcare toolkit among autistic patients and their primary care providers.

\section{METHODS}

\section{Community-Academic Partnership}

The Academic Autism Spectrum Partnership in Research and Education (AASPIRE; http://aaspire.org/) is an ongoing academic-community partnership comprising academic researchers, autistic adults, family members, and healthcare and disability services providers. We use a CBPR approach, whereby academic and community partners serve as equal partners throughout each project. In this study, partners were involved with the development of the research question, the design of the study, the creation of protocols and research materials, the development of the toolkit, the analysis and interpretation of data, and the writing of this manuscript. ${ }^{13,14}$ The project was approved by the institutional review boards at each affiliated university.

\section{Participants and Recruitment}

For all three studies, participants needed to be 18 years old or older, reside in the United States, and communicate in English. Additional eligibility criteria for autistic adults were a medical diagnosis on the autism spectrum (autistic disorder, Asperger's, pervasive developmental disorder not otherwise specified, or autism spectrum disorder) and, in the toolkit evaluation study, a designated PCP. We encouraged autistic adults to participate directly, with or without help from a supporter. In cases where the autistic adult could not participate directly, even with accommodations and supports, we asked a supporter who had experience supporting the autistic adult in healthcare settings to participate on their behalf. For the cognitive interview study, PCPs' eligibility included a current primary care practice with adult patients. In the toolkit evaluation study, PCPs were included only if their patient participated in the study. We recruited participants via fliers, postings, and announcements to autism and disability-related organizations, email distribution lists, recruitment databases, and forums. Potential participants completed a brief screening questionnaire online or via telephone to assess eligibility.

\section{Toolkit Content Development}

The content of the toolkit was informed by a prior series of AASPIRE studies, including 1) a survey comparing the healthcare experiences ${ }^{10}$ and barriers to care ${ }^{11}$ of 209 autistic and 228 non-autistic adults, 2) a qualitative study of the healthcare experiences of 39 autistic adults and 16 supporters, ${ }^{12}$ and 3 ) a brief survey about the autism-related practices and training needs of 129 PCPs for adults, and qualitative interviews with 9 PCPs about their experiences in providing care to autistic adults (unpublished data). These data helped us identify potential leverage points that could be targeted with our intervention and informed the types of tools and resources to include. Table 1 depicts some of the concrete ways those findings informed the toolkit.

Our team of academic and community partners jointly created and edited materials to ensure their relevance, utility, and accessibility. In general, we found that our autistic participants and team members desired a high degree of detail and examples, especially on topics related to navigating the healthcare system. The resulting AASPIRE Healthcare Toolkit has a section for patients and supporters and another for healthcare providers. It includes general healthcare and autism-related information, checklists, worksheets, and other resources. Figure 1 shows sample toolkit contents; the full toolkit is available at http://autismandhealth.org.

Recognizing the substantial heterogeneity of autistic individuals, our research participants and team members felt that communicating personalized information about each individual patient was essential. ${ }^{12}$ The toolkit's 
Table 1 Examples of How Findings from Prior Studies Informed Toolkit

\begin{tabular}{|c|c|}
\hline Finding & How it informed toolkit \\
\hline Great heterogeneity in what autistic patients need and recommend & Development of AHAT to create personalized accommodations reports \\
\hline $\begin{array}{l}\text { PCPs disclose low confidence in ASD-related skills, but do not have time } \\
\text { to attend training }\end{array}$ & $\begin{array}{l}\text { Online format for PCP educational materials; AHAT reports provide } \\
\text { actionable, patient-specific information }\end{array}$ \\
\hline $\begin{array}{l}\text { Making appointments may be difficult or impossible for some autistic } \\
\text { patients }\end{array}$ & $\begin{array}{l}\text { AHAT letter can include request to help patient make appointment; "How } \\
\text { to Make Appointments" section on patient portion of website; "Making an } \\
\text { Appointment Worksheet" for patients }\end{array}$ \\
\hline $\begin{array}{l}\text { Waiting room can be hard to tolerate for autistic patients; some patients/ } \\
\text { systems have found ways to address issues (e.g. headphones, private } \\
\text { areas, call to patient when ready) }\end{array}$ & $\begin{array}{l}\text { AHAT includes section about waiting room accommodations; information } \\
\text { about waiting room challenges and accommodations on both patient and } \\
\text { provider sections of website; "What to Bring to a Healthcare Visit } \\
\text { Checklist" includes items to help make waiting room more tolerable }\end{array}$ \\
\hline $\begin{array}{l}\text { Providers often make false assumptions about patients' communication } \\
\text { needs and abilities or ignore written communication }\end{array}$ & $\begin{array}{l}\text { AHAT section describing patients' ability to speak, read, and write, use of } \\
\text { AAC, and other communication-related information; AHAT response } \\
\text { options re need for written communication; educational materials re } \\
\text { communication issues on provider section of website }\end{array}$ \\
\hline $\begin{array}{l}\text { Challenges with communication can greatly impede care; communication } \\
\text { accommodations are often a key component of successful encounters }\end{array}$ & $\begin{array}{l}\text { AHAT section about accommodations to help with expressive and } \\
\text { receptive communication; educational information about communication } \\
\text { issues in ASD on provider section of website }\end{array}$ \\
\hline $\begin{array}{l}\text { Sensory issues (e.g. sensitivity to lights, sounds, touch, or smells) can be } \\
\text { barrier to care }\end{array}$ & $\begin{array}{l}\text { AHAT section response options for accommodations to address sensory } \\
\text { issues; "What to Bring to a Healthcare Visit Checklist" includes items to } \\
\text { help with sensory needs; patient and PCP educational materials about } \\
\text { sensory issues on website }\end{array}$ \\
\hline $\begin{array}{l}\text { Slow processing speed can be barrier to real-time interactions with } \\
\text { healthcare provider }\end{array}$ & $\begin{array}{l}\text { AHAT response options related to needing extra time to process } \\
\text { information; information about processing speed issues on provider } \\
\text { section of website; "Symptoms Worksheet" to help patients collect } \\
\text { thoughts prior to a visit }\end{array}$ \\
\hline Patients' challenges with body awareness can impede care & $\begin{array}{l}\text { AHAT response options informing provider about challenges with body } \\
\text { awareness; educational materials re body awareness on provider section of } \\
\text { website }\end{array}$ \\
\hline $\begin{array}{l}\text { Patients experience great challenges navigating the health system and } \\
\text { following up on recommendations }\end{array}$ & $\begin{array}{l}\text { AHAT sections on accommodations to help patients follow-up on care; } \\
\text { patient information section about navigating the healthcare system; "After } \\
\text { the Visit Worksheet" for patients to collect information needed to follow- } \\
\text { up on care }\end{array}$ \\
\hline $\begin{array}{l}\text { Providers often do not appropriately incorporate supporters; doing so is a } \\
\text { key component to many successful interactions }\end{array}$ & AHAT section listing supporters and noting desired role for each \\
\hline $\begin{array}{l}\text { Patients experience discrimination and stigma related to ASD; may not } \\
\text { wish to disclose ASD to providers }\end{array}$ & $\begin{array}{l}\text { Patient section of website includes pros and cons of disclosing diagnosis, } \\
\text { tips for how to talk to people about it and for coping with discrimination, } \\
\text { and information about laws protecting people with disabilities; provider } \\
\text { section of website includes information about what ASD is and is not, and } \\
\text { dispels common myths; entire toolkit uses strengths-based approach and } \\
\text { non-discriminatory language }\end{array}$ \\
\hline
\end{tabular}

AHAT Autism Healthcare Accommodations Tool, PCP primary care provider, ASD autism spectrum disorder

centerpiece is thus the Autism Healthcare Accommodations Tool (AHAT), which allows patients to create a personalized accommodations report for their healthcare provider. A patient or his/her supporter completes the AHAT survey to automatically generate a customized cover letter and AHAT report for the provider.

We used the recommendations elicited in our qualitative studies and the lived and professional experience of the community and academic partners on our team to create the AHAT survey items. We created two versions of the survey, one for autistic adults and one for supporters. The AHAT survey includes five multiple-choice items about the patient's spoken and written communication abilities and use of alternatives to speech, and 12 items about areas where autistic adults may need strategies and accommodations to facilitate care, or where providers may need to be aware of autism-related characteristics. Each of these items uses a check-all response format and lists 5 to 14 potential accommodations, strategies, or characteristics, an option indicating that no accommodations are needed, and one indicating that accommodations are needed but not listed. There are also open-ended items related to patients' strengths, special interests, and strategies for recognizing and addressing anxiety in healthcare settings and a section eliciting information about supporters. Table 2 further describes the AHAT. The final version of the full AHAT survey and samples of AHAT reports are provided in Appendix A.

\section{Preliminary Testing and Refinement of the AHAT}

We assessed content validity of the AHAT survey and reports by conducting cognitive interviews with autistic adults, supporters, and PCPs. We also informally reviewed the AHAT reports with several local groups of PCPs and autism experts. Participants could choose to take part in the cognitive interviews in person or via telephone, email, or text-based chat. We used purposeful sampling to ensure that we included autistic participants with a broad range of disability characteristics. The interviewer showed autistic participants or supporters the AHAT survey items, and showed providers a sample cover letter and sample reports from three hypothetical patients. The interviewer used a variety of qualitative 


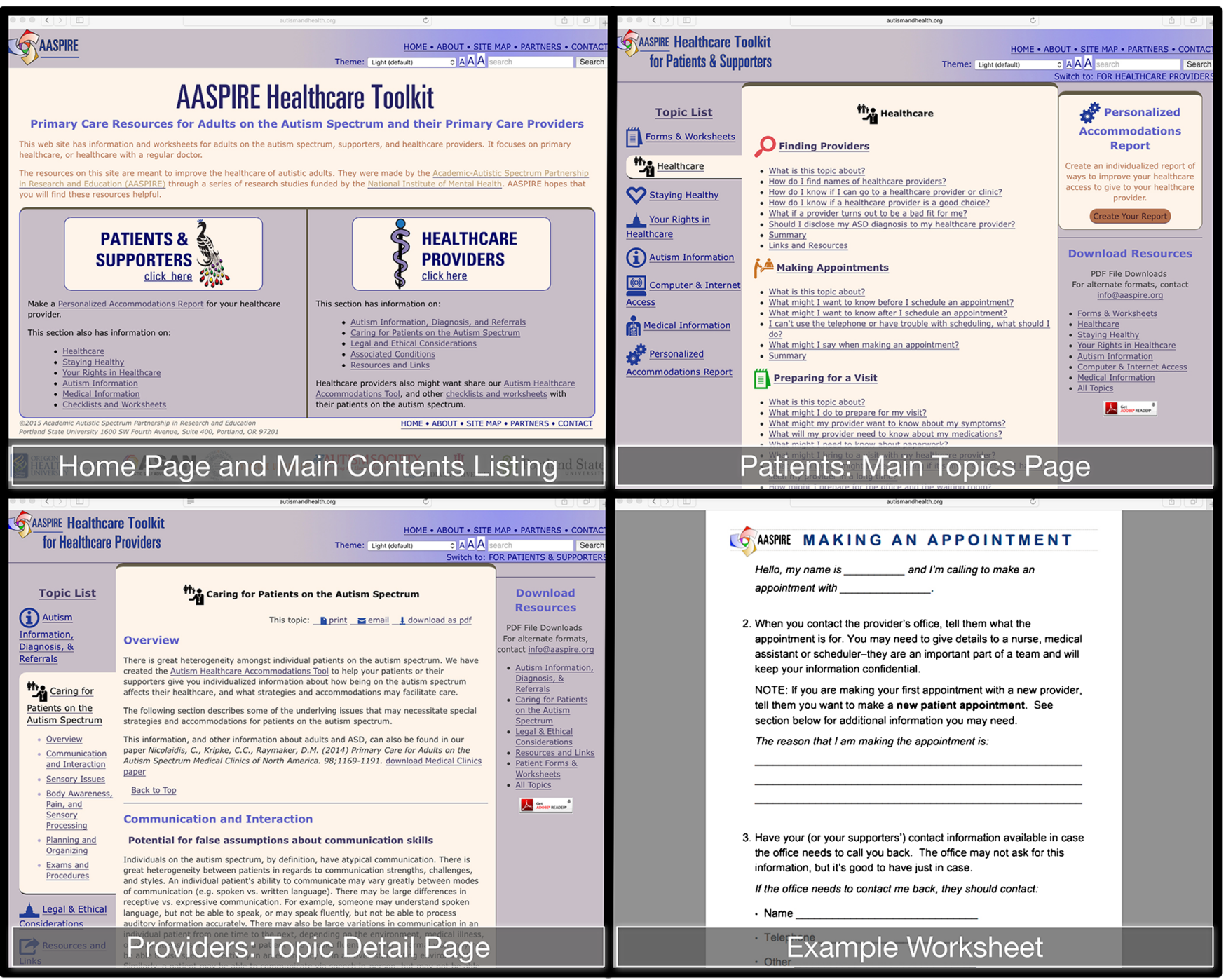

Figure 1 Examples of toolkit contents.

techniques to assess understanding, relevance, and utility, including asking participants to paraphrase items or response options, asking them to describe what potential accommodations might look like in their own situation, and eliciting ideas for additional strategies not already included in the AHAT. The interviewer took notes on the responses and entered them into a matrix. We used an iterative process, periodically reviewing participant responses to the cognitive interview questions, revising the surveys, reports, and letters based upon feedback, and showing later participants the most current versions. We also went back to some of the PCP participants to assess whether our changes adequately addressed their concerns.

We then conducted a 2 -week test-retest reliability study with autistic participants and supporters to test the stability of the tool over time. Taking each response option for the check-all items as a separate dichotomous variable, the original AHAT included 132 variables. For each of the 132 variables, we calculated the percentage of time given by participants to the same response on the two versions of the survey, as well as a kappa and a phi statistic for each.

\section{Toolkit Evaluation}

Study Design. We evaluated the full toolkit in a real-life setting using a mixed-methods, single arm pre/postintervention study design. After completing a baseline survey, autistic participants (or their supporters) used the AHAT tool to create a personalized report and decided whether to have it sent to their PCP. They then gained access to the remainder of the online toolkit. One month after using the toolkit, participants completed a post-intervention survey. In cases where participants asked us to send the AHAT report to their provider, we surveyed PCPs approximately 1 month after the intervention to assess whether they found the report useful.

Data Collection. We conducted surveys with autistic participants using an online audio computer-assisted survey 
Table 2 Autism Healthcare Survey and Report Contents

\begin{tabular}{|c|c|}
\hline Section & Topics covered \\
\hline \multicolumn{2}{|l|}{ AHAT Survey } \\
\hline $\begin{array}{l}\text { How you } \\
\text { communicate }\end{array}$ & $\begin{array}{l}\text { Ability to understand spoken language, speak, read, and write; } \\
\text { use of alternative and augmentative communication }\end{array}$ \\
\hline $\begin{array}{l}\text { Communication } \\
\text { suggestions }\end{array}$ & $\begin{array}{l}\text { Potential accommodations to help patient with receptive and } \\
\text { expressive communication; characteristics provider should be } \\
\text { aware of related to communication }\end{array}$ \\
\hline Before the visit & $\begin{array}{l}\text { Potential accommodations staff can make prior to visit (e.g. re } \\
\text { scheduling); accommodations to help patient handle waiting } \\
\text { room }\end{array}$ \\
\hline During the visit & $\begin{array}{l}\text { Potential accommodations to help patient stay calm and } \\
\text { comfortable, handle examinations or procedures, and } \\
\text { participate in shared decision-making; other autism-related } \\
\text { characteristics provider should be aware of }\end{array}$ \\
\hline After the visit & $\begin{array}{l}\text { Accommodations to help patient understand or follow } \\
\text { recommendations; ability to use telephone; if needed, } \\
\text { accommodations to handle blood draws }\end{array}$ \\
\hline Getting to know you & $\begin{array}{l}\text { Information about patient's strengths and special interests; } \\
\text { information to recognize and address anxiety during office } \\
\text { visits }\end{array}$ \\
\hline Your supporters & $\begin{array}{l}\text { Name and contact information for up to } 5 \text { supporters; } \\
\text { relationship to patient and preferred role for each one; name of } \\
\text { guardian/conservator and/or healthcare power of attorney, if } \\
\text { applicable }\end{array}$ \\
\hline Sharing the report* & $\begin{array}{l}\text { Name, date of birth, preferred gender pronoun, need for } \\
\text { assistance with scheduling or transportation, }\end{array}$ \\
\hline \multicolumn{2}{|l|}{ AHAT Report } \\
\hline Cover letter & $\begin{array}{l}\text { Introduction to report; need for assistance with scheduling or } \\
\text { transportation; link to full online toolkit }\end{array}$ \\
\hline Main AHAT report & $\begin{array}{l}\text { Information about patient communication; recommended } \\
\text { strategies and accommodations to help visits go smoothly, help } \\
\text { patient tolerate exams, assist with shared decision-making, } \\
\text { help patient comply with recommendations; information to } \\
\text { help better understand patient }\end{array}$ \\
\hline $\begin{array}{l}\text { Information for } \\
\text { office staff }\end{array}$ & $\begin{array}{l}\text { Recommendations for setting up appointments, helping patient } \\
\text { tolerate wait, rooming patient, and assisting patient with blood } \\
\text { draws }\end{array}$ \\
\hline $\begin{array}{l}\text { Supporter } \\
\text { information }\end{array}$ & $\begin{array}{l}\text { Name of conservator/guardian and/or healthcare power of } \\
\text { attorney, if applicable; table with name, relationship, } \\
\text { healthcare role, and contact information for each supporter }\end{array}$ \\
\hline
\end{tabular}

* Data are shown for public version of the AHAT. Research study version of the AHAT also asked whether participant wished to share the report. If yes, we requested information about the provider's name and contact information; if not, there was an open-ended item asking why participant chose not to send report. Research version also included 4 multiple-choice and 1 open-ended item evaluating the AHAT

interview (ACASI) system that has been found to be highly accessible to people with developmental disabilities. ${ }^{15,16}$ Surveys had two versions, one for autistic adults participating directly and one for supporters. The supporter version asked questions about the autistic person in the third person and instructed the supporter, where applicable, to either answer on behalf of the autistic person or offer their own opinion. The surveys are provided in Appendix B.

We assessed healthcare self-efficacy using a 21-item scale created de novo by our community and academic partners, with special attention to the self-efficacy issues previously identified in our qualitative work. ${ }^{12}$ Items addressed aspects related to healthcare navigation, successful interactions with providers, and disease self-management. Response options used a four-point Likert scale with anchors of " 0 - Not at all confident" to " 3 - Totally confident." We scored self-efficacy by adding responses from the 21 items, resulting in a possible range of 0 to 63 , with higher scores corresponding to higher self-efficacy.

\section{Item description}

5 multiple choice items

3 items in check-all that apply format; each item has 9-11 accommodations/characteristics as well as options to indicate none are needed or none apply

2 items in check-all that apply format; each item has 6-8 accommodations as well as options to indicate none are needed or none apply

4 items in check-all that apply format; each item has 5-13 accommodations/characteristics as well as options to indicate none are needed or none apply

2 items in check-all that apply format; each item has 9-10 accommodations/characteristics as well as options to indicate none are needed or none apply; 2 dichotomous items 5 open-ended items

For each supporter: open-ended items for contact information; multiple-choice item for relationship; check-all item for preferred roles. Dichotomous and open-ended items re guardian and power of attorney

Open-ended item for name; 1 multiple-choice and 2 dichotomous items 
agree." We analyzed items by summing the responses to yield a composite score from 8 to 40 , with higher scores indicating higher satisfaction.

The pre-intervention survey also included information about demographic and disability characteristics. The postintervention survey included seven multiple-choice items and nine open-ended items assessing the autistic patient's or supporter's impression of the toolkit's usability and utility.

In cases where participants asked us to send their AHAT report to their PCPs and provided enough information for us to locate the PCP, we mailed the PCP an information sheet about the study, a cover letter, and the AHAT report. A month later, we attempted to contact the PCP to recruit them to the study. Due to an initial low response rate, we shortened the PCP survey to fit on a single page. Likert-scale and open-ended items assessed the PCP's impression of the AHAT report and the toolkit. PCPs could participate in the survey via telephone, fax, email, or Internet.

Data Analysis. We calculated summary statistics for all measures. We calculated Cronbach's alphas for scored scales (patient-provider communication and healthcare selfefficacy). We could not do so for the barriers checklist or the AHAT survey because responses were dichotomous or in check-all format. We compared pre- and post-intervention outcomes using paired $t$ tests. We conducted all quantitative analyses using Stata software (version 13.0; StataCorp LP, College Station, TX).

We conducted a thematic analysis ${ }^{22}$ of responses to openended survey items using an inductive approach, on a semantic level, and a constructivist paradigm. The two co-principal investigators (CN, DR) reviewed all responses using an electronic spreadsheet, collaboratively devised a coding schema, categorized responses, collapsed codes into common themes, and chose representative quotes.

\section{RESULTS}

Participant characteristics for all three studies are presented in Table 3. Approximately half of the participants were men, most were non-Hispanic white, and 59-70\% participated independently. Approximately half lived in their own home and half with family or in group homes. Approximately onethird of participants almost always required assistance in healthcare settings, a third required it frequently, and a third required it rarely or never. Most PCPs practiced internal medicine or family medicine.

\section{Preliminary Testing and Refinement of the AHAT}

Autistic participants consistently indicated that the AHAT was important and that they were able to paraphrase the items being tested and elaborate on how or why potential accommodations would or would not be useful to them. Most felt that all their necessary accommodations were included in the available options. Based on participant feedback, we made minor changes to the introduction and to the wording of a few items on the survey. All PCPs indicated that the content of the report was very helpful, but some PCPs looking at earlier versions thought it would be difficult to access the information. We revised the AHAT report format multiple times until we found one that maximized ease of use for PCPs.

In 2-week test-retest comparisons, participants answered AHAT items similarly $80 \%$ of the time (autistic mean 0.803 , SD 0.08; supporter mean 0.799, SD 0.08). We reviewed 21 items $(16 \%)$ where responses matched less than $70 \%$ of the time or where the kappa or phi statistics were below 0.4 . We decided to make minor modifications to simplify three items/ response options, remove 11 response options, and keep the other seven response options.

\section{Toolkit Evaluation Study}

Almost all autistic participants and supporters felt that the AHAT and the toolkit were easy to use, important, and useful. Over $90 \%$ said they would recommend the healthcare toolkit to a friend or their healthcare provider (see Table 4).

In pre/post-intervention comparisons, the total number of barriers encountered by patients decreased significantly (from a mean of 4.07 at baseline to 2.82 post-intervention; $p<$ 0.001 ). Participants' self-efficacy in navigating the healthcare system also increased (37.92 to $39.39, p=0.02$; see Table 5).

We identified several themes from patients' open-ended answers that may help explain how the toolkit affected outcomes. First, participants described the toolkit as giving them a means to clarify and communicate their needs. For example, one participant wrote, "Filling out the survey helped me clarify some things of which I was only vaguely aware. It also helped put into words things I am unable to communicate because I cannot think of the right words."

Similarly, many participants felt that the toolkit validated their experience and empowered them to self-advocate more effectively. For example, one wrote, "It was validating. Previously, I felt that some of the things I was doing, like bringing support with me, was a sign of weakness. Now, I view it as part of accommodation. It also gave me some ideas of things to try that I hadn't thought of." Another explained, "I used my iPad to communicate with [provider] at the beginning of the visit.... It is a fairly new provider for me so it was helpful to establish the accommodations I need. It gave me the confidence to make the changes I need to communicate my issues effectively."

Participants also often gave examples of how the toolkit improved their self-efficacy, especially by helping them prepare for visits. One participant wrote, "It takes away a lot of my uncertainty about the appointments. Whether I'll bring up everything I want to bring up, whether I asked the right questions about follow-up care, and being prepared for talking to new doctors. It's a game changer for me."

Most participants were enthusiastic about how the AHAT report might affect their $P C P s^{\prime}$ behavior. For example, one 
Table 3 Participant Characteristics

\begin{tabular}{|c|c|c|c|}
\hline Autistic adults & Cognitive interviews, $n=\mathbf{3 0}$ & Test-retest reliability, $n=59$ & Toolkit evaluation, $n=170$ \\
\hline \multicolumn{4}{|l|}{ Study participation } \\
\hline Participated directly, independently & $20(66.7 \%)$ & $35(59.3 \%)$ & $123(70.2 \%)$ \\
\hline Participated directly with support & Not recorded & $7(11.9 \%)$ & $18(10.2 \%)$ \\
\hline Participated via supporter (proxy) & $10(33.3 \%)$ & $17(28.8 \%)$ & $34(19.4 \%)$ \\
\hline Age: mean, in years (range; STD) & $37.6(20-64 ; 13.6)$ & $34.6(18-64 ; 11.5)$ & $36.5(18-68 ; 12.9)$ \\
\hline \multicolumn{4}{|l|}{ Sex } \\
\hline Male & $14(46.7 \%)$ & $30(50.9 \%)$ & $75(44.1 \%)$ \\
\hline Female & $16(53.3 \%)$ & $24(40.7 \%)$ & $91(53.5 \%)$ \\
\hline Other & & $5(8.5 \%)$ & $4(2.4 \%)$ \\
\hline \multicolumn{4}{|l|}{ Race } \\
\hline White & $25(83.3 \%)$ & $52(89.7 \%)$ & $152(89.4 \%)$ \\
\hline Black & $4(13.3 \%)$ & $2(3.5 \%)$ & $5(2.9 \%)$ \\
\hline Multiracial & $1(3.3 \%)$ & $3(5.2 \%)$ & $5(2.9 \%)$ \\
\hline Other & 0 & $1(1.7 \%)$ & $8(4.8 \%)$ \\
\hline Ethnicity - Latino & $1(3.3 \%)$ & $2(3.5 \%)$ & $11(6.5 \%)$ \\
\hline \multicolumn{4}{|l|}{ Educational attainment } \\
\hline High school or Less & $12(40.0 \%)$ & $18(30.5 \%)$ & $32(18.9 \%)$ \\
\hline Some college (no degree) & $10(33.3 \%)$ & $13(22.0 \%)$ & $43(25.4 \%)$ \\
\hline Associate or bachelor's degree & $7(23.3 \%)$ & $16(27.1 \%)$ & $63(37.3 \%)$ \\
\hline Masters or $\mathrm{PhD}$ degree & $1(3.3 \%)$ & $12(20.3 \%)$ & $31(18.3 \%)$ \\
\hline \multicolumn{4}{|l|}{ Living situation } \\
\hline Own place (rent or own) & $13(48.2 \%)$ & $28(47.5 \%)$ & $99(56.9 \%)$ \\
\hline With family & $12(44.4 \%)$ & $24(40.7 \%)$ & $60(34.5 \%)$ \\
\hline Group home or other & $2(7.4 \%)$ & $7(10.9 \%)$ & $15(8.6 \%)$ \\
\hline \multicolumn{4}{|l|}{ Requires assistance to receive healthcare } \\
\hline Always or often & Not asked & $24(40.7 \%)$ & $54(32.3 \%)$ \\
\hline Sometimes & & $18(30.5 \%)$ & $52(31.1 \%)$ \\
\hline Rarely or never & & $17(28.8 \%)$ & $61(36.6 \%)$ \\
\hline \multicolumn{4}{|l|}{ Self-reported health status } \\
\hline Excellent & Not asked & $9(15.3 \%)$ & $26(15.0 \%)$ \\
\hline Very good & & $17(28.8 \%)$ & $51(29.3 \%)$ \\
\hline Good & & $18(30.5 \%)$ & $52(29.9 \%$ \\
\hline Fair & & $15(23.7 \%)$ & $38(21.8 \%)$ \\
\hline Poor & & $1(1.7 \%)$ & $7(4 \%)$ \\
\hline Primary care providers & Cognitive interviews, $n=10$ & Not applicable & Toolkit evaluation, $n=41$ \\
\hline Age: mean, in years (range; STD) & $41.6(27-61 ; 11.8)$ & & $36.3(28-62 ; 9,2)$ \\
\hline \multicolumn{4}{|l|}{ Sex } \\
\hline Male & $6(60 \%)$ & & $15(37.5 \%)$ \\
\hline Female & $4(40 \%)$ & & $25(62.5 \%)$ \\
\hline \multicolumn{4}{|l|}{ Degree } \\
\hline $\mathrm{MD} / \mathrm{DO}$ & $10(100 \%)$ & & $35(85.4 \%)$ \\
\hline NP/PA & 0 & & $6(14.6 \%)$ \\
\hline \multicolumn{4}{|l|}{ Specialty } \\
\hline Family medicine/general practice & 0 & & $26(63.4 \%)$ \\
\hline General internal medicine & $8(80 \%)$ & & $9(22.0 \%)$ \\
\hline Pediatrics & 0 & & $2(2.4 \%)$ \\
\hline Med/Peds & $1(10 \%)$ & & $1(2.4 \%)$ \\
\hline Other & $1(10 \%)$ & & $3(7.3 \%)$ \\
\hline \multicolumn{4}{|l|}{ Practice setting } \\
\hline Solo or single specialty private practice & 0 & & $18(47.4 \%)$ \\
\hline Multi-specialty group practice & 0 & & $9(23.7 \%)$ \\
\hline Staff model HMO & 0 & & $5(13.2 \%)$ \\
\hline Academic health center & $7(70 \%)$ & & $4(10.5 \%)$ \\
\hline Other & $3(30 \%)$ & & $2(5.3 \%)$ \\
\hline Training in autism or developmental disabilities & $1(10 \%)$ & & $7(18.4 \%)$ \\
\hline
\end{tabular}

wrote, "Y'all sent things to the doctor so MAYBE THIS TIME he'll listen to me." However, some were concerned that providers would be unlikely to pay attention to the AHAT report ("Not confident that healthcare provider(s) will take it seriously."). A minority of participants voiced concerns that their PCP would have a negative response. For example, one wrote, "When I asked my psychiatrist to not use air fresheners she said she had to or else her office smelled, and she acted like it was a really big burden on her. I think that if I handed your nice letter to my physicians ... they would think I am asking too much of them. I already stand out; I don't want to stand out more."
Sixty-five percent of participants gave permission for us to mail their AHAT report to their PCP. Thirty-five participants answered an open-ended item about why they chose not to have their report sent, indicating that they planned on taking the report to the PCP themselves $(n=8)$, were in the process of changing or did not have a PCP $(n=8)$, did not need it $(n=6)$, did not wish to disclose their ASD to their PCP $(n=4)$, had privacy concerns $(n=2)$, had technical problems seeing the report (due to a temporary problem with our server; $n=2$ ), or didn't like the report or worried that their PCP would not react well to it $(n=3)$. Comments on the post-intervention surveys 
Table 4 Patient and Provider Impressions of the Toolkit 1 Month After Use

\begin{tabular}{|c|c|}
\hline Evaluation item & $\begin{array}{l}\text { Autistic adults }(n=126) \text {, number }(\%) \text { of } \\
\text { responses }\end{array}$ \\
\hline \multicolumn{2}{|c|}{$\begin{array}{l}\text { How much of the information in the Healthcare Toolkit was easy to } \\
\text { understand (with help if needed)? }\end{array}$} \\
\hline a. Less than half & $1(0.8 \%)$ \\
\hline b. About half & $5(4.1 \%)$ \\
\hline c. Most & $40(32.5 \%)$ \\
\hline d. All or almost all & $77(62.6 \%)$ \\
\hline \multicolumn{2}{|c|}{ How important is the information in the Healthcare Toolkit? } \\
\hline a. Not important & $4(3.2 \%)$ \\
\hline \multicolumn{2}{|l|}{ important } \\
\hline \multirow{2}{*}{\multicolumn{2}{|c|}{$\begin{array}{l}\text { c. Very important } 79(63.2 \%) \\
\text { How useful was the information in the Healthcare Toolkit? }\end{array}$}} \\
\hline & \\
\hline a. Very useful & $63(51.6 \%)$ \\
\hline b. Somewhat useful & $53(43.4 \%)$ \\
\hline c. Not useful & $6(4.9 \%)$ \\
\hline \multicolumn{2}{|c|}{ Would you recommend the Healthcare Toolkit to a friend? } \\
\hline a. Yes & $105(92.1 \%)$ \\
\hline b. No & $9(7.9 \%)$ \\
\hline \multicolumn{2}{|c|}{ Would you recommend the Healthcare Toolkit to healthcare providers? } \\
\hline & $111(94.9 \%)$ \\
\hline \multirow{3}{*}{$\begin{array}{l}\text { a. No } \\
\text { b. No }\end{array}$} & $6(5.1 \%)$ \\
\hline & PCPs $(n=41)$ \\
\hline & $\mathrm{N}(\%)$ \\
\hline \multicolumn{2}{|c|}{ How useful was the information in the accommodations report? } \\
\hline a. Very useful & $9(23.1 \%)$ \\
\hline b. Moderately useful & $23(59.0 \%)$ \\
\hline c. Slightly useful & $6(15.4 \%)$ \\
\hline d. Not useful & $1(2.6 \%)$ \\
\hline \multicolumn{2}{|c|}{$\begin{array}{l}\text { Would you recommend the Autism Healthcare Accommodations Tool to } \\
\text { other patients on the autism spectrum? }\end{array}$} \\
\hline a. No & $5(13.5 \% 0$ \\
\hline b. Yes & $32(86.5 \%)$ \\
\hline
\end{tabular}

indicated that several additional patients had taken their AHAT reports to their PCPs.

Among the 43 patients who saw their PCP within the 1month follow-up period, satisfaction with PCP communication improved significantly (from 30.9 to $32.6, p=0.03$; Table 5). Comments from participants who had seen their PCPs in the intervening month described many concrete positive changes in providers or their staff:

"I brought a copy of the accommodation letter in case he had not received it. He had and it was already scanned into his computer. He went over it with me and did what had been recommended.... I was reassured by the doctor taking the accommodation letter seriously.... I felt like some of the difficulties I experience were addressed and that they wouldn't have been had I not made use of the Healthcare Toolkit."

And a supporter described the effect the AHAT report had on her daughter's care:

I think the Toolkit validated that my concerns and my daughter's "issues" (sensory, behavioral, etc.) which often presented during medical appointments were typical for ASD patients and should be accommodated.

Several participants voiced frustration that their providers did not read the AHAT report or did not make any changes based on the report (e.g. "It was disregarded :-("). However, patients gave no examples of PCPs responding negatively to the report. In addition, a few participants indicated that they already had a good relationship with their PCPs and thus did not need the AHAT. "The visit went fine but it seemed to me that it only brought to attention things that were already known as I have a very close relationship with my healthcare provider." Participants offered numerous suggestions for minor changes to the toolkit or additional content that could be included. Many also requested that we create a version for other types of providers such as dentists, psychiatrists, and medical subspecialists.

We were able to send AHAT reports to 88 PCPs, 41 (47\%) of whom completed the survey. Most PCPs rated it as moderately or very useful and indicated that they would recommend it to their patients (Table 4). Most answers from PCPs to openended questions were positive and provided examples of the tool's utility (e.g. "Extremely helpful. What I needed were specific, but concise suggestions regarding how to make my patient more comfortable. The report will be in her chart and I will use it at each visit.") However, several PCPs noted that they already were doing what was recommended in the report

Table 5 Change in Outcomes Between Pre- and Post-Intervention Surveys

\begin{tabular}{|c|c|c|c|c|c|c|}
\hline Outcome & Description & Number* & $\begin{array}{l}\text { Pre-intervention, } \\
\text { mean (SD) }\end{array}$ & $\begin{array}{l}\text { Post-intervention, } \\
\text { mean (SD) }\end{array}$ & $\begin{array}{l}\text { Effect size, } \\
\text { Cohen's } d\end{array}$ & $p$ value \\
\hline Barriers to healthcare & $\begin{array}{l}\text { Total number of barriers to } \\
\text { healthcare, from a checklist of } 16^{\dagger} \\
\text { barriers }\end{array}$ & 108 & 4.07 (2.549) & $2.82(1.976)$ & -0.55 & $<0.0001$ \\
\hline $\begin{array}{l}\text { Healthcare self- } \\
\text { efficacy }\end{array}$ & $\begin{array}{l}21 \text {-items using } 0-3 \text { Likert scale; } \\
\text { summed score; range } 0-62 \text {; alpha } \\
0.92\end{array}$ & 98 & $37.92(12.021)$ & $39.39(11.803)$ & 0.12 & 0.016 \\
\hline $\begin{array}{l}\text { Patient-provider } \\
\text { communication }\end{array}$ & $\begin{array}{l}8 \text { items using } 1-5 \text { Likert scale; } \\
\text { summed score; range } 8-40 \text {; alpha } \\
0.92\end{array}$ & 43 & $30.91(6.414)$ & $32.63(6.612)$ & 0.26 & 0.027 \\
\hline
\end{tabular}

* Data shown only for autistic adults who participated directly (with or without support) in both pre- and post-intervention tests and had no missing data on the outcome measure. Data gathered from proxies were not included in these analyses due to differences in how questions for items were posed. Given the small number of individuals who participated by proxy, those data are not shown separately. Patient-provider communication questions were asked only among participants who had a visit with their PCP during the 1-month follow-up period

${ }^{\dagger}$ Due to an error in the survey software, responses about two different barriers were combined into one field, thus reducing the total possible barriers from 16 to 15 
(e.g. "Reinforces what I had learned to be effective"), and two PCPs felt that they did not have time to implement accommodations (e.g. "In a busy primary care office the time demands are immense. This creates further time demands.").

\section{DISCUSSION}

Autistic adults face many challenges when trying to access healthcare services, including locating disability-competent providers, understanding and navigating the health system, and obtaining the necessary accommodations for their communication, cognitive, emotional regulation, and sensory needs. We developed tools to help autistic people and their healthcare providers address these challenges. Our CBPR process resulted in a healthcare accommodation tool with good content validity and test-retest reliability, and a highly accessible and usable healthcare toolkit. Most patients and PCPs indicated that the tools were useful in facilitating care. Quantitative results indicate that the toolkit has the potential to reduce barriers to healthcare and improve healthcare selfefficacy and patient-provider communication. Qualitative results suggest that these improvements may have been driven by heightened self-awareness and enhanced self-advocacy, as well as changes in patient and provider behaviors.

To the best of our knowledge, this is the first intervention specifically developed to improve primary care services for autistic adults. Our findings suggest that the toolkit may act on several potential leverage points critical to improving healthcare. Many of the qualitative responses focused on the effect the toolkit had in helping participants name the challenges they experience with healthcare and understand them as issues commonly experienced by others on the spectrum. Importantly, for some participants, it also seems to have helped reframe these issues, to view them not as personal weaknesses, but as disability-related needs that can and should be accommodated. This type of patient empowerment appeared to be particularly helpful when combined with practical resources and tools that participants could use to prepare for visits or for following recommendations. A strong body of literature documents the importance of patient activation and empowerment. ${ }^{23,24}$ Our study points to a potential means of increasing empowerment and activation in autistic patients.

But patient empowerment must be coupled with changes in provider attitudes, skills, and behaviors. We designed the toolkit using a model in which PCPs seek information about a specific autistic patient on a "needto-know" basis. Evaluation data support the notion that many PCPs found the AHAT reports useful. Though it is likely that an accommodation report may not be not sufficient to eliminate all constraints affecting PCPs' ability to care for their autistic patients, our hope is that the AASPIRE Healthcare Toolkit will be a first step toward the larger training and system changes necessary to adequately address the healthcare needs of autistic adults.

Our project has several limitations. The focus was primarily on developing the toolkit and conducting a preliminary evaluation of its feasibility, acceptability, potential effects, and mechanisms of action. The evaluation study was not designed to rigorously test the effectiveness of the toolkit in changing health or healthcare outcomes. Our use of non-systematic recruitment methods could have biased the sample toward participants who were more open to this type of intervention. We did not seek to independently confirm ASD diagnoses, but felt that the potential inclusion of people who were misdiagnosed with ASD was consistent with the real-world primary care setting in which the toolkit will be used. As with many studies of PCPs, we had a modest response rate; it is possible that PCPs who did not find the toolkit useful were less likely to respond.

Despite these limitations, our project has several important implications: 1) Individual patients and clinicians may benefit from using the AASPIRE Healthcare Toolkit. Though targeted to autistic adults in primary care settings, in our clinical experience, several of the resources and tools have also been helpful in facilitating care in hospital and specialty care settings and with patients with other developmental disabilities or low healthcare literacy. Similarly, though tested exclusively with adults, such tools may aid in transitioning autistic youth to the adult healthcare system. 2) Providers should make every effort to fulfill their legal obligation to provide accommodations to autistic patients, and should support patients' efforts at self-advocacy, self-efficacy, and selfmanagement. 3) Healthcare systems should try to find ways to incorporate such tools into their clinical protocols, training initiatives, and electronic medical records. 4) The CBPR process was a key element in developing relevant, useful, and accessible tools. Other groups attempting to develop and test interventions for marginalized or difficult-to-reach populations should consider using a CBPR approach. 5) Further research is needed to rigorously test the effectiveness of such interventions in changing health or healthcare outcomes.

\section{Acknowledgments:}

Contributions: We are indebted to the entire AASPIRE team, including W. Cody Boislair, PhD, and Toby Rates, JD, for their contributions throughout the project. We would also like to thank the Healthcare Subcommittee of the Oregon Commission on Autism Spectrum Disorders for providing input on the toolkit content at multiple stages during the development process. We appreciate the Autistic Self Advocacy Network, the Autism Society of Oregon, and the many other individuals and organizations that helped with recruitment and dissemination. Eight of the participants who took part in the toolkit evaluation via a supporter were recruited with the assistance of the Interactive 
Autism Network (IAN) Research Database at the Kennedy Krieger Institute and Johns Hopkins Medicine. We thank Marcie Tedlow and Angie Mejia for their contributions to project management and data collection. Finally, we thank all the participants who helped shape and evaluate the toolkit. The views expressed in this article are those of the authors and do not necessarily represent the views of the Department of Veterans Affairs.

Corresponding Author: Christina Nicolaidis, MD, MPH; Regional Research Institute, School of Social WorkPortland State University, 1600 SW 4th Ave, Suite 900, Portland, OR 97201, USA (e-mail: Nicol22@pdx.edu).

\section{Compliance with Ethical Standards}

Funding: This study was funded by the National Institute of Mental Health (R34MH092503).

Prior Presentations: Portions of this paper were presented at the 2015 TASH conference in Portland, OR, December 2015.

Conflict of Interest: The authors declare that they have no conflict of interest.

Note: We understand that language describing autism spectrum disorders is controversial, and we respect the many valid opinions on this issue. We choose to use identity-first language (e.g. autistic adult) instead of person-first language (e.g. person with autism) due to the preferences of the autistic self-advocacy community. ${ }^{25}$.

\section{REFERENCES}

1. Bruder MB, Kerins G, Mazzarella C, Sims J, Stein N. Brief report: the medical care of adults with autism spectrum disorders: identifying the needs. J Autism Dev Disord. 2012;42(11):2498-2504

2. Brugha TS, McManus S, Bankart J, et al. Epidemiology of autism spectrum disorders in adults in the community in England. Arch Gen Psychiatry. 2011;68(5):459-465.

3. Fombonne E. Epidemiology of pervasive developmental disorders. Pediatr Res. 2009;65(6):591-598.

4. Lai M-C, Baron-Cohen S. Identifying the lost generation of adults with autism spectrum conditions. Lancet Psychiatry. 2015;2(11):1013-1027.

5. Shattuck PT, Roux AM, Hudson LE, Taylor JL, Maenner MJ, Trani J-F. Services for adults with an autism spectrum disorder. Can J Psychiatr. 2012;57(5):284.

6. Croen LA, Zerbo O, Qian Y, et al. The health status of adults on the autism spectrum. Autism. 2015;19(7):814-823.

7. Fortuna RJ, Robinson L, Smith TH, et al. Health conditions and functional status in adults with autism: a cross-sectional evaluation. J Gen Intern Med. 2015;1-8.

8. Nicolaidis C, Kripke CC, Raymaker D. Primary care for adults on the autism spectrum. Med Clin N Am. 2014;98(5):1169-1191.
9. Zerbo O, Massolo ML, Gian Y, Croen LA. A study of physician knowledge and experience with autism in adults in a large integrated healthcare system. J Autism Dev Disord. 2015;45(12):4002-4014.

10. Nicolaidis C, Raymaker D, McDonald $\mathbf{K}$, et al. Comparison of healthcare experiences in autistic and non-autistic adults: a cross-sectional online survey facilitated by an academic-community partnership. J Gen Intern Med. 2013;28(6):761-769.

11. Raymaker D, Nicolaidis C, McDonald K, et al. Barriers to healthcare: instrument development and comparison between adults on the autism spectrum and adults with and without other disabilities. Under review.

12. Nicolaidis C, Raymaker DM, Ashkenazy E, et al. "Respect the way I need to communicate with you": healthcare experiences of adults on the autism spectrum. Autism. 2015;19(7):824-831.

13. Nicolaidis C, Raymaker D, McDonald K, Dern S, Ashkenazy E, Boisclair WC, Robertson S, Baggs A. Collaboration strategies in non-traditional CBPR partnerships: lessons from an academic-community partnership with autistic self-advocates. Prog Community Health Partnersh. 2011;5(2): 143-150.

14. Raymaker D, Nicolaidis C, Boisclair WC, et al. Community based participatory research methods in co-developing an accessible Web site for end users on the autism spectrum. Under review.

15. Oschwald M, Renker PR, Hughes RB, Arthur A, Powers LE, Curry MA Development of an accessible audio computer-assisted self-interview (ACASI) to screen for abuse and provide safety strategies for women with disabilities. J Interpers Violence. 2009;24(5):795-818.

16. Oschwald M, Leotti S, Raymaker DM, et al. Development of an audiocomputer assisted self-interview to investigate violence and health in the lives of people with developmental disabilities. Disabil Health J. 2014;7(3):292-301.

17. Hong T. Internet health information in the patient-provider dialogue. Cyberpsychol Behav. 2008;5:587-589.

18. Cantor D, Covell J, Davis T., Park I, Rizzo L. Health Information National Trends Survey (HINTS) 2007: Final Report. 2009, Available at: http:// hints.cancer.gov/docs/HINTS2007FinalReport.pdf. Accessed May 18, 2016.

19. Marks R, Ok H, Joung H, Allegrante JP. Perceptions about collaborative decisions: perceived provider effectiveness among 2003 and 2007 Health Information National Trends Survey (HINTS) respondents. J Health Commun. 2010;15(Suppl 3):135-146.

20. Ok H, Marks R, Allegrante JP. Perceptions of health care provider communication activity among American cancer survivors and Adults Without Cancer Histories: an analysis of the 2003 Health Information Trends Survey (HINTS) Data. Journal of Health Communication. 2008; 13(7):637-653.

21. Smith SG, Wolf MS, von Wagner C. Socioeconomic status, statistical confidence, and patient-provider communication: an analysis of the Health Information National Trends Survey (HINTS 2007). J Health Commun. 2010;15(Suppl 3):169-185.

22. Braun V, Clarke V. Using thematic analysis in psychology. Qual Res Psychol. 2006;3(2):77-101.

23. Hibbard $\mathbf{J H}$, Greene $\mathbf{J}$. What the evidence shows about patient activation: better health outcomes and care experiences fewer data on costs. Health Affairs. 2013;32(2):207-214.

24. Johnson MO. The shifting landscape of health care: toward a model of health care empowerment. Am J Public Health. 2011;101(2):265-270.

25. Kapp SK, Gillespie-Lynch K, Sherman LE, Hutman T. Deficit, Difference, or Both? Autism and Neurodiversity. Dev Psychol. 2013;49(1):59-71. 